\title{
KEPUTUSAN PEMBELIAN SECARA ONLINE MELALUI SITUSJUAL BELI SHOPEE DITINJAU DARI KEMUDAHAN, KEPERCAYAAN DAN PERSEPSI RESIKO PADA MAHASISWA UNIBA SURAKARTA
}

\author{
Adinda Galih Nur Wahyudi ${ }^{1}$, Djumali ${ }^{2}$, Eny Kustiyah ${ }^{3}$ \\ Fakultas Ekonomi Program Studi Manajemen \\ Universitas Islam Batik Surakarta \\ Jl. KH. Agus Salim No. 10 Surakarta 57147 \\ adindagalih80@gmail.com
}

\begin{abstract}
This study aims to determine the simultaneous and partial influence of convenience (X1), trust (X2), and risk perception (X3) on online purchasing decisions through the Shopee buying and selling site for UNIBA students in Surakarta. In this study data were collected through observation, interviews, literature studies and.Questionnaries With the help of the IBM SPSS program version 18. Questionnaires were distributed to UNIBA students who had used the Shopee site in Surkarta. The analysis used in this study includes data instrument tests (validity and reliability tests), multiple linear regression analysis, classic assumption tests (normality test, multicollinearity test, heterokedasticity test), and hypothesis testing ( $F$ test, $t$ test, coefficient of determination. The results showed that ease, trust and risk perception significantly influence purchasing decision simultaneously, and prove that ease and trust have a positive and significant effect on purchasing decisions, while risk perception has a negative and significant effect on purchasing decisions.
\end{abstract}

Keywords: Ease, Trust, Risk Perception and Decision to Purchase.

\section{PENDAHULUAN}

Seiring dengan perkembangan arus globalisasi disegala bidang baik teknologi informasi, kesehatan hingga ekonomi mengalami perkembangan sangat pesat menciptakan peluang baru dalam bidang ekonomi yaitu, dalam bidang jual-beli online.

Kebutuhan pembelian secara online melalui sistem elektronik seperti internet. Peran internet sangat berpengaruh dalam kehidupan manusia. Pengguna bisa dengan mudah mengakses berbagai macam layanan informasi secara efisien dan mendapatkan produk dengan mudah tanpa harus bertemu tatap muka secara langsung dengan penjual yang biasa disebut e-commerce (electronic commerce). (Syahrizal, Arief, Khabibah, Niaga, \& Malang, 2019)

Marketplace merupakan salah satu jenis e-commerce yang sedang berkembang saat ini. Marketplace dapat diartikan sebagai tempat dimana penjual dapat membuat akun dan menjual berbagai macam barang dagangan yang akan dijual. Fasilitas dan keuntungan juga diberikan secara cuma cuma oleh pelaku marketplace. Salah satu yang bisa didapat dari berjualan menggunakan marketplace ini adalah penjual tidak perlu membuat situs dan toko online pribadi yang tentunya membutuhkan biaya yang lebih.

Oleh karena itu, penelitian ini diperlukan untuk menganalisis kualitas layanan yang diberikan oleh Shopee apakah mempengaruhi kemudahan, kepercayaan, persepsi resiko dan keputusan pembelian, (Asosiasi Penyedia Jasa Internet Indonesia, 2017). 
Dalam hal keputusan pembelian, konsumen tidak akan lepas dari proses pengambilan keputusan, oleh karena itu pemasar harus melakukan tahap-tahap dari pengambilan keputusan tersebut. Perusahaan yang mampu memahami kebutuhan dan keinginan konsumen akan mendorong perilaku konsumen untuk melakukan keputusan pembelian, hal ini dikarenakan perilaku konsumen merasa sesuai dengan yang diharapkan (Triana, Puji, Bambang, Sudarwati, 2018).

Shopee merupakan salah satu mobile marketplace yang menerapkan bentuk Customer to Customer (C2C) yang mana model bisnis seperti ini sangat tergantung oleh pihak ke-3 sebagai penerima dan penyalur uang. Shopee memfasilitasi transaksi online sekaligus dengan metode pembayarannya. Jika toko online yang tidak bertanggung jawab atas transaksi penjual dan pembeli, maka dimodel Marketplace ini shopee juga ikut terlibat dan bertanggung jawab. Jadi selama barang yang dibeli belum sampai ke alamat tujuan pembeli, uang akan aman karena ditahan terlebih dahulu oleh pihak shopee, pihak Shopee akan mengembalikan uang kepada pihak jika terjadi kegagalan dalam proses transaksi. Pentingnya Shopee pada kalangan mahasiswa sangat memudahkan pencarian barang yang diinginkan karena terdapat fitur filter yang akan membantu pengguna aplikasi Shopee.

Berdasarkan latar belakang permasalahan diatas dapat ditarik perumusan masalah adalah Bagaimana kemudahan, kepercayaan dan persepsi resiko berpengaruh secara simultan terhadap keputusan pembelian secara online melalui situs jual beli Shopee pada mahasiswa UNIBA Surakarta.

\section{LANDASAN TEORI}

\section{Keputusan Pembelian}

Dalam mengenal konsumen perlu mempelajari perilaku konsumen sebagai perwujudan dari seluruh aktivitas jiwa manusia dalam kehidupan sehari-hari. Presepsi-presepsi pengaruh orang lain dan motivasi-motivasi internal akan berinteraksi untuk menentukan keputusan terakhir yang dianggap paling sesuai (Rosvita, 2010). Setiap keputusan akan membuat pilihan terakhir, dapat berupa tindakan atau opini yang akan kita jalankan.

\section{Kemudahan}

Menurut (Fachrizi Alwafi, 2016), Kemudahan atau perceived of use dipersepsikan sebagai sebuah tingkat diamana seseorang menyakini bahwa penggunaan teknologi merupakan hal yang mudah dan tidak memerlukan usaha keras dari pemakainya. Konsep ini mencakup kejelasan tujuan penggunaan teknologi dan kemudahan penggunaan sistem sesuai dengan keinginan pemakai. Dari beberapa definisi diatas kemudahan penggunaan dalam melakukan transaksi online merupakan keyakinan seseorang dalam melakukan transaksi online tanpa mengalami kendala dan bebas dari masalah.

\section{Kepercayaan}

Salah satu faktor penting dalam loyalitas pelanggan adalah dengan membangun kepercayaan dalam hubungan jangka panjang. Kepercayaan ini tidak begitu saja dapat diakui oleh pihak lain atau mitra bisnis, melainkan harus dibangun mulai dari awal dan dapat 
dibuktikan. Menurut (Tjiptono, Fandy \& Chandra, 2012), ketika konsumen mempercayai sebuah perusahaan, mereka akan lebih suka melakukan pembelian ulang dan membagi informasi pribadi yang berharga kepada perusahaan tersebut.

\section{Persepsi Resiko}

Persepsi akan resiko adalah sebuah ketidakpastian yang dihadapi oleh konsumen ketika mereka tidak bisa meramalkan konsekuensi dimasa yang akan datang atas keputusan pembelian yang konsumen lakukan. Persepsi juga dapat diartikan sebagai penilaian subjektif oleh seseorang terhadap kemungkinan dari sebuah kejadian kecelakaan dan seberapa khawatir individu dengan konsekuensi atau dampak yang ditimbulkan kejadian tersebut. (Nursani, Arifin, \& Hufron, 2018)

\section{METODOLOGI PENELITIAN}

Penelitian ini merupakan penelitian analisis deskriptif yang menggunakan metode regresi berganda. Dalam penelitian ini hanya menggunakan empat variabel yaitu Kemudahan, Kepercayaan, Persepsi Resiko dan Keputusan Pembelian. Dalam penelitian ini peniliti menggunakan responden 100 konsumen yang sudah berbelanja secara online melalui situs jual beli Shopee pada mahasiswa UNIBA di Surakarta.

Penelitian ini menggunakan teknik Non Probability Sampling dengan cara Sampling Purposive. Dimana peneliti menggunakan pertimbangan sendiri secara sengaja dalam memilih anggota populasi yang dianggap sesuai dalam memberikan informasi yang dibutuhkan harus memenuh kriteria sebagai berikut (1) penggunaan internet mahasiswa UNIBA, (2) pernah berbelanja online di Shopee, dan (3) memiliki perangkat jaringan internet untuk mengakses situs.

\section{HASIL DAN PEMBAHASAN}

\section{Uji Asumsi Klasik}

\section{a. Uji Normalitas}

Uji normalitas data dalam sebuah penelitian mempunyai tujuan untuk menguji apakah dalam model regresi, variabel terikat dan variabel bebas keduanya mempunyai distribusi normal atau tidak. Model regresi yang baik adalah yang memiliki distribusi normal atau mendekati normal.

Tabel IV.11

Hasil Uji Nomalitas

\begin{tabular}{c|c|c|c}
\hline Variabel & $\begin{array}{c}\text { Kolmogorov- } \\
\text { Smimov }\end{array}$ & Sign. & Keterangan \\
\hline $\begin{array}{c}\text { Unstandardized } \\
\text { Residual }\end{array}$ & 0,911 & 0,378 & $\begin{array}{c}\text { Data terdistribusi } \\
\text { nomal }\end{array}$ \\
\hline
\end{tabular}


Dari hasil pengujian Kolmogorov-Smirnov pada tabel IV.11 menunjukan bahwa nilai signifikansi yang dihasilkan 0,378 lebih besar dari 0,05 sehingga data dalam penelitian ini memiliki sebaran data yang normal.

a. Uji Multikolinieritas

Uji multiikolinieritas dalam sebuah penelitian bertujuan untuk menguji apakah ditemukan kolerasi antar variabel bebas. Uji multikolinieritas dapat dilihat dari nilai Variance Inflaction Factor (VIF) dan nilai Tolerance masing-masing dari variabel bebasnya. Apabila nilai VIF $<10$ dan nilai Tolerance $>0,1$ maka dapat dinyatakan tidak ada indikasi multikolinearitas antara variabel bebasnya.

Tabel IV.9

Hasil Uji Multikolinearitas

\begin{tabular}{|c|c|c|c|}
\hline Variabel & Tolerance & VIF & Kesimpulan \\
\hline Kemudahan & 0,988 & 1,012 & $\begin{array}{c}\text { Tidak terjadi } \\
\text { multikolinearitas }\end{array}$ \\
\hline Kepercayaan & 0,978 & 1,023 & $\begin{array}{c}\text { Tidak terjadi } \\
\text { multikolinearitas }\end{array}$ \\
\hline Persepsi resiko & 0,976 & 1,025 & $\begin{array}{c}\text { Tidak terjadi } \\
\text { multikolinearitas }\end{array}$ \\
\hline
\end{tabular}

Berdasarkan data tabel diatas, dapat dilihat bahwa nilai tolerance X1 sebesar 0,988, X2 sebesar 0,978 dan X3 sebesar 0,976 dimana nilai tolerance tersebut lebih besar dari 0,1 dan nilai VIF dari X1 sebesar 1,012, X2 sebesar 1,023 dan X3 sebesar 1,025 dimana nilai VIF kurang dari 10, sehingga dapat disimpulkan bahwa dalam penelitian ini tidak ada multikolinearitas antar variabel independent dalam model regresi.

b. Uji Heterokedastisitas

Uji heteroskedastisitas ini digunakan untuk mengetahui apakah semua variabel bebas mempunyai varian kesalahan pengganggu yang sama dalam model regresi. Uji heteroskedastisitas dalam penelitian ini menggunakan uji Glejser. Kriteria dari uji ini yaitu jika $t_{\text {hitung }}>t_{\text {tabel }}$ atau $t_{\text {hitung }}<t_{\text {tabel }}(\mathrm{sig} .<0,05)$ berarti terjadi heteroskedastisitas. Sebaliknya jika $-t_{\text {tabel }}<t_{\text {hitung }}<t_{\text {tabel }}($ sig. $>0,05)$ berarti tidak terjadi heteroskedastisitas.

\begin{tabular}{lccccc}
\multicolumn{5}{c}{ Tabel IV.10 } \\
& Hasil Uji Heteroskedastisitas & \\
\hline \multicolumn{1}{c}{ Variabel } & $\mathrm{t}_{\text {hitung }}$ & $\mathrm{t}_{\text {tabel }}$ & Sig & $\alpha$ & Kesimpulan \\
\hline Kemudahan & 1,048 & 1,985 & 0,297 & 0,05 & Tidak terjadi \\
Kepercayaan & 0,136 & 1,985 & 0,892 & 0,05 & Tidak terjadi \\
Persepsi resiko & 0,078 & 1,985 & 0,938 & 0,05 & Tidak terjadi \\
\hline Sumber-: output olah data (2019) & & &
\end{tabular}

Berdasarkan hasil tersebut pada tingkat signifikasi 5\%, semua koefisien regresi tersebut tidak signifikan (yaitu dengan tingkat signifikansi > 0,05), 
sehingga dapat disimpulkan bahwa variabel fungsi kemudahan, kepercayaan dan persepsi resiko tidak terjadi heteroskedastisitas dalam persamaan.

\section{Analisis Data}

a. Analisis Regresi Linear Berganda

Berdasarkan hasil pengolahan data model regresi dengan program SPSS versi 18 dijelaskan dalam hasil pengolahan data sebagai berikut:

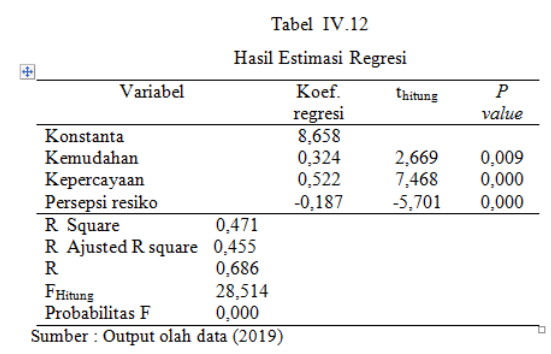

Berdasarkan tabel diatas dapat diketahui nilai koefisien regresi, maka dapat disusun analisis regresi sebagai berikut:

$\mathrm{Y}=8,658+0,324 \mathrm{X}_{1}+0,522 \mathrm{X}_{2}-0,187 \mathrm{X}_{3}$

Dari persamaan tersebut dapat dijelaskan bahwa:

a. Variabel kemudahan, kepercayaan dan persepsi resiko mempunyai arah koefisien yang bertanda positif terhadap keputusan pembelian dengan nilai sebesar 8,658.

b. Koefisien kemudahan memberikan nilai positif 0,324 berarti bahwa jika semakin mudah pembelian maka akan semakin tinggi keputusan pembelian dengan asumsi variabel lain tetap maka keputusan pembelian akan mengalami peningkatan sebesar $1: 0,324$.

c. Koefisien kepercayaan memberikan nilai positif yang berarti bahwa jika semakin tinggi kepercayaan dengan asumsi variabel lain tetap maka keputusan pembelian akan mengalami peningkatan sebesar $1: 0,522$.

d. Koefisien perspesi resiko memberikan nilai negatif yang berarti bahwa jika persepsi resiko semakin tinggi dengan asumsi variabel lain tetap maka keputusan pembelian akan mengalami penurunan sebesar 1:0,187.

Hasil perhitungan diatas dapat diketahui bahwa variabel yang paling dominan mempengaruhi keputusan pembelian responden shopee adalah variabel fungsi kepercayaan karena memiliki nilai sebesar 0,522.

b. Hasil Koefisien Determinasi $\mathrm{R}^{2}$

Hasil dari koedfisien determinasi $\mathrm{R}^{2}$ dapat dilihat pada output analisis data sebagai berikut:

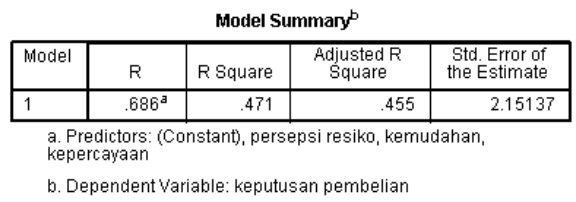

Sumber : Data primer diolah 2019 
Berdasarkan hasil analisis diatas diperoleh nilaai Adjusted $R$ Square $\left(R^{2}\right)$ sebesar 0,455 atau 45,5\%. Artinya variabel kemudahan, kepercayaan dan persepsi resiko memiliki pengaruh sebesar $45,5 \%$ terhadap keputusan pembelian secara online melalui situs jual beli Shopee pada mahasiswa UNIBA di Surakarta. Sedangkan sisanya sebesar 54,5\% dipengaruhi oleh variabel lain yang tidak diajukan dalam penelitian ini.

\section{PEMBAHASAN}

Penelitian yang telah dilakukan tentang keputusan pembelian secara online melalui situs jual beli shopee ditinjau dari kemudahan, kepercayaan dan persepsi resiko pada mahasiswa UNIBA yang ditampilkan dalam persamaan hasil regresi yaitu $\mathrm{Y}=8,658+0,324 \mathrm{X}_{1}+0,522$ $\mathrm{X}_{2}-0,187 \mathrm{X}_{3}$. Artinya nilai konstanta (b1) adalah 0,324; jika kemudahan bernilai 0, maka keputusan pembelian bernilai positif 0,324 . Nilai koefisien regresi variabel kepercayaan $\left(b_{2}\right)$ bernilai positif, yaitu 0,522 ; artinya setiap peningkatan kepercayaan responden sebesar 1 point akan meningkatkan juga keputusan pembelian sebesar 0,522 dengan asumsi variabel yang lain nilainya tetap. Nilai koefisien regresi variabel persepsi resiko $\left(b_{3}\right)$ bernilai negatif, yaitu 0,187 ; artinya setiap persepsi penurunan resiko sebesar 1 point akan meningkatkan keputusan pembelian sebesar 0,187 dengan asumsi variabel yang lain nilainya tetap.

Hasil uji hipotesis pertama dengan uji $\mathrm{F}$ memperoleh nilai $\mathrm{F}_{\text {hitung }}>\mathrm{F}_{\text {tabel }}(28,514>2,699)$ pada taraf signifikansi 5\%, maka kemudahan, kepercayaan dan persepsi resiko secara bersama-sama berpengaruh positif terhadap keputusan pembelian. Dengan hasil tersebut berarti nilai $P$-valuenya lebih kecil dari tingkat kesalahan sebesar 0,05, yang berartib bahwa kemudahan, kepercayaan dan persepsi resiko berpengaruh secara simultan atau bersama-sama terhadap keputusan pembelian secara online melalui situs jual beli shopee. Kemudahan, kepercayaan dan persepsi resiko dengan keputusan pembelian, dapat diartikan bahwa semakin baik kemudahan, semakin tinggi kepercayaan dan semakin kecil persepsi resiko pada suatu situs jejaring sosial maka akan semakin tinggi pula keputusan pembelian konsumen yang mana kemudahan, kepercayaan pelanggan dan persepsi resiko akan mempengaruhi dari keputusan pembelian konsumen itu sendiri.

\section{KESIMPULAN}

Berdasarkan hasil penelitian yang telah dilakukan, maka penulis dapat menyimpulkan tentang beberapa hal antara lain sebagai berikut:

a. Berdasarkan penelitian terdapat pengaruh secara simultan variabel kemudahan, kepercayaan dan persepsi resiko terhadap variabel keputusan pembelian shopee. Hal ini bisa disimpulkan jika variabel kemudahan dan kepercayaan mengalami peningkatan maka keputusan pembelian juga akan semakin kuat, begitu pula dengan variabel persepsi resiko yaitu apabila persepsi resiko tinggi maka akan menurunkan keputusan pembelian.

b. Variabel kemudahan $\left(\mathrm{X}_{1}\right)$ secara parsial berpengaruh positif dan signifikan terhadap keputusan pembelian (Y). Jadi, semakin mudah melakukan pembelanjaan shopee maka akan semakin meningkatkan keputusan pembelian responden. 
c. Variabel kepercayaan $\left(\mathrm{X}_{2}\right)$ secara parsial berpengaruh positif dan signifikan terhadap keputusan pembelian (Y). Jadi, semakin tinggi kepercayaan yang diberikan oleh Shopee, semakin tinggi pula keputusan pembelian.

d. Variabel persepsi resiko $\left(\mathrm{X}_{3}\right)$ secara parsial berpengaruh negatif dan signifikan terhadap keputusan pembelian (Y). Jadi, semakin tinggi persepsi resiko dari shopee, maka keputusan pembelian akan mengalami penurunan.

\section{SARAN}

Berdasarkan kesimpulan yang diperoleh dari hasil analisa data, maka dapat peneliti sarankan sebagai berikut :

Kepercayaan berpengaruh dominan terhadap keputusan pembelian. Oleh karena itu, penting bagi situs jual beli shopee untuk meningkatkan kepercayaan yang ada selama ini dimana pihak situs jual beli shopee harus memberikan jaminan, kemudahan penggunaan dengan sebaik mungkin.

Situs jual beli Shopee sebaiknya meningkatkan persepsi resiko dengan lebih memperhatikan point-point persepsi resiko diatas agar kepercayaan konsumen meningkat terhadap pembelian barang secara online, dengan cara meningkatkan pengamanan pada saat bertransaksi melalui website khusus yang berada di facebook dan hanya konsumen yang berkaitan yang bisa mengakses.

\section{DAFTAR PUSTAKA}

Asosiasi Penyedia Jasa Internet Indonesia. (n.d.). Retrieved from www.apjii.com

Fachrizi Alwafi, R. H. M. (2016). Pengaruh Persepsi Keamanan, Kemudahan Bertransaksi, Kepercayaan Terhadap Toko Dan Pengalaman Berbelanja Terhadap Minat Beli Secara Online Pada Situs Jual Beli Tokopedia.Com. Journal of Management, 5(2), 1-15.

Lembang, R. D. (2010). Analisis Pengaruh Kualitas Produk, Harga, Promosi dan Cuaua Keputusan Pembelian Teh Siap Minum dalam Kemasan Merek Teh Botol Sosro.

Nursani, Arifin, R., \& Hufron, M. (2018). Analisis Pengaruh Kepercayaan, Keamanan, Harga, Kualitas Pelayanan, dan Persepsi Akan Resiko Terhadap Keputusan Pembelian Pada Konsumen E-Commerce Melalui Shopee (Studi Pada Mahasiswa Unisma). Jurnal Ekonomi Bisnis, 102-115.

Syahrizal, M., Arief, I., Khabibah, U., Niaga, A., \& Malang, P. N. (2019). ANALISIS PENGARUH KEMUDAHAN DAN KEPERCAYAAN PENGGUNAAN e-commerce SHOPEE TERHADAP. 161-164.

Tjiptono, Fandy \& Chandra, G. (2012). Pemasaran Strategik (2nd ed.). Yogyakarta: Andi Yogyakarta.

Triana, Puji; Bambang, M. S. (2018). Pengaruh harga, produk, promosi, dan distribusi terhadap keputusan pembelian buku di cv gramera. 18, 227-234. 
Adinda Galih Nur Wahyudi, Djumali, Eny K / Edunomika Vol. 04 No. 01 (Februari 2020) 